\title{
Clinical Study \\ Routine Use of Color Doppler in Fetal Heart Scanning in a Low-Risk Population
}

\section{Torbjørn Moe Eggebø, ${ }^{1}$ Claudia Heien, ${ }^{1}$ Magne Berget, ${ }^{2}$ and Christian Lycke Ellingsen ${ }^{3}$}

${ }^{1}$ Department of Obstetrics and Gynecology, Stavanger University Hospital, N-4068 Stavanger, Norway

${ }^{2}$ Department of Pediatrics, Stavanger University Hospital, N-4068 Stavanger, Norway

${ }^{3}$ Department of Pathology, Stavanger University Hospital, N-4068 Stavanger, Norway

Correspondence should be addressed to Torbjørn Moe Eggebø, tme@lyse.net

Received 14 February 2012; Accepted 19 March 2012

Academic Editors: K. Chan and E. Cosmi

Copyright (C) 2012 Torbjørn Moe Eggebø et al. This is an open access article distributed under the Creative Commons Attribution License, which permits unrestricted use, distribution, and reproduction in any medium, provided the original work is properly cited.

\begin{abstract}
Objectives. To investigate the detection rate of major fetal heart defects in a low-risk population implementing routine use of color Doppler. Material and Methods. In a prospective observational study, all women undergoing fetal heart scanning (including 6781 routine examinations in the second trimester) during a three-year period were included. First a gray-scale scanning was performed including assessment of the four-chamber view and the great vessels. Thereafter three cross-sectional planes through the fetal thorax were assessed with color Doppler. Results. Thirty-nine fetuses had major heart defects, and 26 (67\%) were prenatally detected. In 9/26 (35\%) of cases the main ultrasound finding was related to the use of color Doppler. The survival rate of live born children was $91 \%$. Conclusions. Routine use of color Doppler in fetal heart scanning in a low-risk population may be helpful in the detection of major heart defects; however, still severe malformations were missed prenatally.
\end{abstract}

\section{Introduction}

The incidence of cardiac defects is estimated to be 8 per 1000 births, and annually around 36,000 children are live born with heart defects in the European Union [1]. The incidence of major congenital cardiac defects is approximately 3-4 per 1000 live births and 5 per 1000 fetuses in the second trimester [2]. Prenatal diagnosis of major malformations by ultrasonography may lower the perinatal mortality [3, 4], allowing for better planning of the delivery and postnatal care [5]. The prenatal detection rate of major heart defects varies from $5 \%$ to $75 \%$ in low-risk populations [6-11]. The detection rate depends on the sonographers education and experience $[12,13]$. Although it is possible to identify situations with increased risk for cardiac malformations, most fetal cardiac defects appear in the low-risk population, and the overall detection rate of major heart defects is still not satisfactory $[14,15]$. The use of color Doppler is recommended when a heart defect is suspected [16], but the effectiveness of routine use in low-risk populations is not documented and remains controversial [17]. Routine use of color Doppler is not implemented in second trimester scanning guidelines from the International Society of Ultrasound in Obstetrics and Gynecology (ISUOG) [18]. In American Institute of Ultrasound in Medicine (AIUM) guidelines for 2011, color Doppler is regarded as an optional method, but recommended for suspected cardiac flow abnormalities [19]. For safety reasons routine use of pulsed color Doppler is advised against in the first trimester [20]. We aimed to investigate the detection rate of major heart defects in a low-risk population implementing the routine use of color Doppler in second and third trimester fetal heart scanning and to focus on the main ultrasound findings responsible for the detection of the anomalies.

\section{Patients and Methods}

2.1. Patients. We performed a prospective observational study at the Stavanger University Hospital from May 2006 to July 2009. Routinely the use of color Doppler was implemented in fetal heart scanning in the second and third 
trimester. The ultrasound laboratory at the hospital is classified as a secondary-level unit. All pregnant women in Norway are recommended to have a second-trimester ultrasound scanning in pregnancy week $17-20$, and the examination is free of charge. Around $60 \%$ of the women in the region attend the routine scan at the hospital, and the rest attend the scan at their private gynecologist. Private gynecologists in the region do not routinely use color Doppler. During the study period 6781 women attended a second trimester routine scan at the hospital. The local Ethics Committee approved the study, and all women attending the routine scan gave written informed consent.

2.2. Methods. Six midwives educated for scanning performed the routine examinations using EUB Hitachi 5500 (Kashiwa, Japan), Voluson 730 Pro or Voluson 730 Expert (GE Medical Systems, Kretz, Austria) devices with 3.5-7.5$\mathrm{MHz}$ multifrequency transabdominal transducers. Examinations before or after the routine scan were performed by physicians or midwives and only on medical indications. Before the start of the study, the midwives were briefly trained on using color Doppler. First an extended grayscale fetal heart scanning was performed as recommended in ISUOG's guidelines [18]. Thereafter color Doppler was added, and three cross-sectional planes through the fetal thorax were assessed: the four-chamber, five-chamber, and the three-vessel trachea view as described by Yagel et al. [21]. A new scan was performed two weeks later if a proper visualization during the routine scan failed. If a fetal heart defect was suspected, an obstetrician performed a thorough fetal examination and fetal karyotyping was offered. In cases with uncertain diagnosis the women were referred to the National Center for Fetal Medicine in Trondheim for an extended examination.

2.3. Follow-Up. In the geographical region there is only one labour ward with around 4500 deliveries yearly and one pediatric department. Heart surgery is not performed at the hospital, but the pediatric unit is responsible for the follow up of all patients. Children with intrauterine suspected heart malformations underwent echocardiography within the first days after delivery, and the final diagnoses were based on postnatal cardiac echocardiography and operative findings. If the pregnancy was terminated and in cases with intrauterine fetal death (IUFD), a thorough autopsy was performed and the findings were compared with the ultrasound findings. In three cases with termination of pregnancy (TOP), autopsy was not performed due to lack of consent from the parents. The ultrasound diagnoses from the National Centre for Fetal Medicine were then used as the final diagnosis. Women referred from private gynecologists because of suspected heart defects are not included in the study population.

2.4. Classification of Heart Defects. The defects were classified as major when they were potentially lethal, when they were severe enough to warrant TOP, or when surgical repair was required and minor when no intervention was likely. The classification of major or minor heart defects in live born children was performed one year after the end of the inclusion period.

\section{Results}

Thirty-nine fetuses examined at the hospital during the study period had major heart defects, and 26 (67\%) were prenatally detected. Of these, $19 / 39(49 \%)$ were detected at the second trimester routine scan, $3 / 39(8 \%)$, were detected before the routine scan and 4/39 (10\%) were detected later in pregnancy. The karyotyping was abnormal in 10 cases. Of the prenatally detected fetuses, one died during pregnancy, one died short time after delivery, and in thirteen cases the pregnancy was terminated. Eleven children with prenatally diagnosed heart defects underwent open-heart surgery, and of those $64 \%$ (7/11), were referred to a center with heart surgery before labour. Details of the ultrasound findings, the final diagnosis, associated anomalies, and outcomes in prenatal diagnosed cases are presented in Table 1. One case with right aortic arch was also diagnosed, but not classified as a major heart defect.

There were no major discrepancies between ultrasound findings and autopsy or postnatal findings (Table 1). A major heart defect was confirmed in all cases admitted to the National Center for Fetal Medicine. In some cases the ultrasound examination at the tertiary center, the postnatal findings, or the autopsy gave additional information, leading to a more precise final diagnosis. There were no "falsepositive" ultrasound findings leading to an unwarranted termination of pregnancy.

Thirteen cases included in the routine scan at the hospital turned out having prenatally undiagnosed major heart anomalies. Two died during pregnancy, one shortly after delivery, seven underwent open-heart surgery, and in three cases with moderate pulmonary stenosis balloon dilatation was performed. Detailed information is presented in Table 2.

In all, 23/39 (59\%) children with major heart defects were born alive and the survival rate of live born children was $91 \%$. Two children died shortly after birth, both with trisomy 13 . The surgical repair was successful in all operated children, and they were in good condition one year after the operation.

The main ultrasound finding responsible for the spotting of the heart defect was unequal size of the ventricles in four cases, unilateral perfusion of right ventricle in three, common atrioventricular valve in three, atrioventricular insufficiency in four, overriding vessel in two, parallel vessels in three, one great vessel in "three-vessel view" in four, retrograde blood flow in "three-vessel view" in two, and abnormal position of the heart in one case (Table 1).

\section{Discussion}

The overall detection rate of major fetal heart defects including routine use of color Doppler was $67 \%$, and $49 \%$ were detected at the routine second trimester scan. Our detection rate was higher than the results in previous Scandinavian studies, but still important malformations were missed. A Swedish study compared first and second trimester detection 
TABLE 1: Main ultrasound finding, secondary findings, final diagnosis, and associated anomalies and outcome in 26 fetuses with major heart anomalies.

\begin{tabular}{|c|c|c|c|c|c|}
\hline $\begin{array}{l}\text { Main ultrasound finding } \\
\text { Ultrasound diagnosis }\end{array}$ & Final heart diagnosis & Karyotype & $\begin{array}{c}\text { Associated } \\
\text { anomalies }\end{array}$ & Time of detection & Outcome \\
\hline \multicolumn{6}{|l|}{ Unequal size of ventricles } \\
\hline Pulmonary stenosis, VSD & Tetralogy of Fallot & & & Routine & Surgical repair \\
\hline $\begin{array}{l}\text { Retrograde flow in aorta, } \\
\text { tricuspid insufficiency }\end{array}$ & $\begin{array}{l}\text { Hypoplastic aortic arch, } \\
\text { CoA }\end{array}$ & & & Late & Surgical repair \\
\hline Septum defect, one great vessel & AVSD, pulmonary atresia & & & Routine & Surgical repair \\
\hline $\begin{array}{l}\text { One great vessel, overriding } \\
\text { artery, VSD }\end{array}$ & Tetralogy of Fallot & Trisomy 13 & & Late & Died after birth \\
\hline \multicolumn{6}{|l|}{$\begin{array}{l}\text { Unilateral perfusion of right } \\
\text { ventricle }\end{array}$} \\
\hline $\begin{array}{l}\text { One great vessel in "three-vessel } \\
\text { view," HLHS }\end{array}$ & HLHS & & & Routine & $\begin{array}{l}\text { TOP (no } \\
\text { autopsy) }\end{array}$ \\
\hline $\begin{array}{l}\text { Retrograde blood flow in aorta, } \\
\text { HLHS }\end{array}$ & HLHS & & & Routine & TOP \\
\hline One outlet vessel, HLHS & HLHS & & & Early & TOP \\
\hline \multicolumn{6}{|l|}{ Common atrioventricular valve } \\
\hline $\begin{array}{l}\text { Septum defect, atrioventricular } \\
\text { insufficiency }\end{array}$ & AVSD & Trisomy 21 & & Routine & TOP \\
\hline Septum defect & AVSD & Trisomy 21 & $\begin{array}{l}\text { Duodenal } \\
\text { atresia }\end{array}$ & Late & Surgical repair \\
\hline Septum defect & VSD & Trisomy 18 & $\begin{array}{l}\text { Multiple } \\
\text { defects }\end{array}$ & Early & TOP \\
\hline \multicolumn{6}{|l|}{ Atrioventricular insufficience } \\
\hline $\begin{array}{l}\text { Tricuspid insufficiency, } \\
\text { retrograde blood flow in DA, } \\
\text { VSD }\end{array}$ & Ebstein's anomaly & & & Routine & TOP \\
\hline $\begin{array}{l}\text { Tricuspid insufficiency, } \\
\text { retrograde blood flow in DA }\end{array}$ & Ebstein's anomaly & & & Routine & $\begin{array}{l}\text { TOP (no } \\
\text { autopsy) }\end{array}$ \\
\hline Tricuspid insufficiency & PA & & TTS & Routine & Surgical repair \\
\hline $\begin{array}{l}\text { Mitral insufficiency, septum } \\
\text { defect, reduced contractility }\end{array}$ & ASD, cardiomegaly & & $\begin{array}{l}\text { Agenesis of } \\
\text { kidneys }\end{array}$ & Routine & TOP \\
\hline \multicolumn{6}{|l|}{ Overriding vessel } \\
\hline VSD & Tetralogy of Fallot & & & Routine & Surgical repair \\
\hline VSD & $\begin{array}{l}\text { Overriding aorta, ASD, } \\
\text { VSD }\end{array}$ & Trisomy 18 & $\begin{array}{l}\text { Clinched } \\
\text { fingers }\end{array}$ & Late & IUFD \\
\hline \multicolumn{6}{|l|}{ Parallel vessels } \\
\hline $\begin{array}{l}\text { TGA, DORV, VSD, tricuspid } \\
\text { insufficiency }\end{array}$ & DORV, TGA, VSD, PA & & & Routine & Surgical repair \\
\hline TGA, DORV, VSD & DORV, TGA & & & Routine & Surgical repair \\
\hline TGA, large VSD & TGA, single ventricle & & Kyphoscoliosis & Routine & TOP \\
\hline \multicolumn{6}{|l|}{$\begin{array}{l}\text { One great vessel in "three-vessel } \\
\text { view" }\end{array}$} \\
\hline Overriding vessel, VSD & DORV, ASD, VSD & Trisomy 21 & & Routine & Surgical repair \\
\hline VSD, tiny pulmonary artery & VSD, pulmonary stenosis & & & Routine & Surgical repair \\
\hline Tricuspid insufficiency & DORV, TGA, VSD & Trisomy 18 & $\begin{array}{l}\text { Clinched } \\
\text { fingers }\end{array}$ & Routine & TOP \\
\hline No other findings & DORV, TGA & & & Routine & $\begin{array}{l}\text { TOP (no } \\
\text { autopsy) }\end{array}$ \\
\hline
\end{tabular}


TABle 1: Continued.

\begin{tabular}{|c|c|c|c|c|c|}
\hline $\begin{array}{l}\text { Main ultrasound finding } \\
\text { Ultrasound diagnosis }\end{array}$ & Final heart diagnosis & Karyotype & $\begin{array}{c}\text { Associated } \\
\text { anomalies }\end{array}$ & Time of detection & Outcome \\
\hline \multicolumn{6}{|l|}{$\begin{array}{l}\text { Retrograde blood flow in } \\
\text { "three-vessel view" }\end{array}$} \\
\hline $\begin{array}{l}\text { Aortic stenosis, retrograde flow } \\
\text { in aorta }\end{array}$ & Aortic stenosis, VSD & & & Routine & Surgical repair \\
\hline Retrograde flow in DA & HRHS, PA & & & Routine & TOP \\
\hline \multicolumn{6}{|l|}{ Abnormal position of the heart } \\
\hline Heart outside thorax & Ectopic heart, VSD & & $\begin{array}{l}\text { Kantrell's } \\
\text { pentalogy }\end{array}$ & Early & TOP \\
\hline
\end{tabular}

of fetal malformations, and $11 \%$ and $15 \%$ of major heart malformations were detected, respectively [10]. In a lowrisk population from northern Norway, $24 \%$ of major heart defects were diagnosed prenatally [8], and in an unselected population examined at the Norwegian National Center for Fetal Medicine, $37 \%$ of major hear defects were detected at the routine scan, and the overall detection rate was 57\% [9]. A study from a teaching hospital in London has reported a very high detection rate without routine use of color Doppler $(75 \%)[6]$.

In the 1990s a systematic examination of the fourchamber view was the basic of the fetal heart scanning [22]. Examining the four-chamber view often fails to detect transposition of the great arteries (TGAs), tetralogy of Fallot, double-outlet right ventricle (DORV), truncus arteriosus communis, and interruption of the aortic arch (IAA) [7]. Assessment of the great vessels by using the three-vessel and trachea view as described by Yagel et al. [21] improves detection rates $[6,23-25]$. ISUOG has published guidelines for the "basic" and the "extended basic" cardiac scan and for a fetal echocardiogram $[16,18]$. Recently the threevessel and trachea view with color flow mapping has been recommended $[17,23]$. Using color Doppler is mandatory in examination of fetuses with suspected heart defects $[16,19]$; however, the value of color Doppler in a low-risk populations is still not documented.

The higher detection rate in our study compared to other Scandinavian studies might be related to the use of color Doppler. However, the study has several limitations. It is performed on a low-risk population, but a selection bias is possible. Some women preferred the routine scan at the hospital, others at their private gynecologists. The examination is free of charge for all; thus, we think this selection is random. The quality of ultrasound devices improves continuously, and the results might be related to better equipment. Both gray-scale scanning and color Doppler were used in all examinations; thus, we cannot reliably distinguish between heart defects detected in gray-scale or by using color Doppler. Our study design was observational without any control group. The study was not designed to compare results from examinations inside and outside the hospital, but the detection rate was much lower in fetuses examined outside the hospital (3/16). A randomized controlled study is necessary before routine use of color Doppler eventually might be recommended.

In a secondary-level unit the most important objective is not to give a precise diagnosis, but spotting an anomaly. Thus, the results of the ultrasound examinations from our hospital (first column in Table 1) focus on the ultrasound findings and not on an exact diagnosis. Fetuses with suspected fetal heart defects should be referred to a tertiary centre for an extended examination [26]. Whenever a ductusarteriosus-dependent heart defect is suspected, delivery at a hospital with heart surgery should be planned. In this study we aimed to focus on the main ultrasound finding leading to the detection of an abnormal heart. An unbalanced four-chamber view, a common AV valve, and an abnormal position of the heart are findings mainly related to grayscale imaging (8/26). Unilateral perfusion of one ventricle, $\mathrm{AV}$ insufficiency, and retrograde flow in one of the vessels in the "three-vessel view" are findings related to the use of color Doppler (9/26). Overriding vessel, parallel vessels, and "one great vessel" in the three-vessel view might be detected in gray-scale (9/26); however, these abnormalities are probably also easier to spot using color Doppler. Figure 1 illustrates a normal-looking gray-scale acquisition of the three-vessel view; however, using color Doppler retrograde flow in the pulmonary artery is obvious. Figure 2 illustrates unilateral perfusion of the right ventricle in a fetus with hypoplastic left heart syndrome (HLHS). The displacement of the tricuspid valve seen in Figure 3 is detectable in grey-scale; however, the tricuspid insufficiency is even easier to spot.

We missed prenatal diagnosing of a major heart defect in thirteen cases, and five of these children were in a serious condition shortly after birth (two cases with IAA, two with coarctation of the aorta (CoA), and one with TGA). All of them were immediately referred to a center for cardiac surgery and successfully operated. Retrospectively, we think the diagnoses in the seven first cases presented in Table 2 have great importance for the newborn child, and the first five 
TABLE 2: Children with major heart defects not detected prenatally.

\begin{tabular}{lccc}
\hline Diagnosis & Karyotype & Associated anomalies & Outcome \\
\hline $\begin{array}{l}\text { Tetralogy of Fallot } \\
\text { Transposition of the great arteries }\end{array}$ & & Surgical repair \\
Double-outlet right ventricle, VSD & Trisomy 13 & $\begin{array}{c}\text { Agenesis of corpus } \\
\text { callosum and cleft } \\
\text { lip/palate }\end{array}$ & $\begin{array}{c}\text { Died three days after } \\
\text { delivery } \\
\text { Surgical repair }\end{array}$ \\
Aortic valve stenosis and IAA & & & $\begin{array}{c}\text { Surgical repair } \\
\text { IAA, aorta stenosis, VSD }\end{array}$ \\
Coarctation of the aorta & 22q11.2 deletion & & Surgical repair \\
Coarctation of the aorta & & Surgical repair \\
Atrioventricular septal defect & Normal & IUFD \\
Ventricular septal defect & Trisomy 18 & Horseshoe kidney & IUFD \\
Ventricular septal defect, mild pulmonary stenosis & & Bilateral pes equino \\
varus & Surgical repair \\
Pulmonary stenosis, VSD & & & Invasive balloon dilatation \\
Pulmonary stenosis, supravalvular aorta stenosis & & Invasive balloon dilatation \\
Pulmonary stenosis & & Invasive balloon dilatation \\
\hline
\end{tabular}

IAA: interrupted aortic arch; VSD: ventricular septal defect; IUFD: intrauterine fetal death.

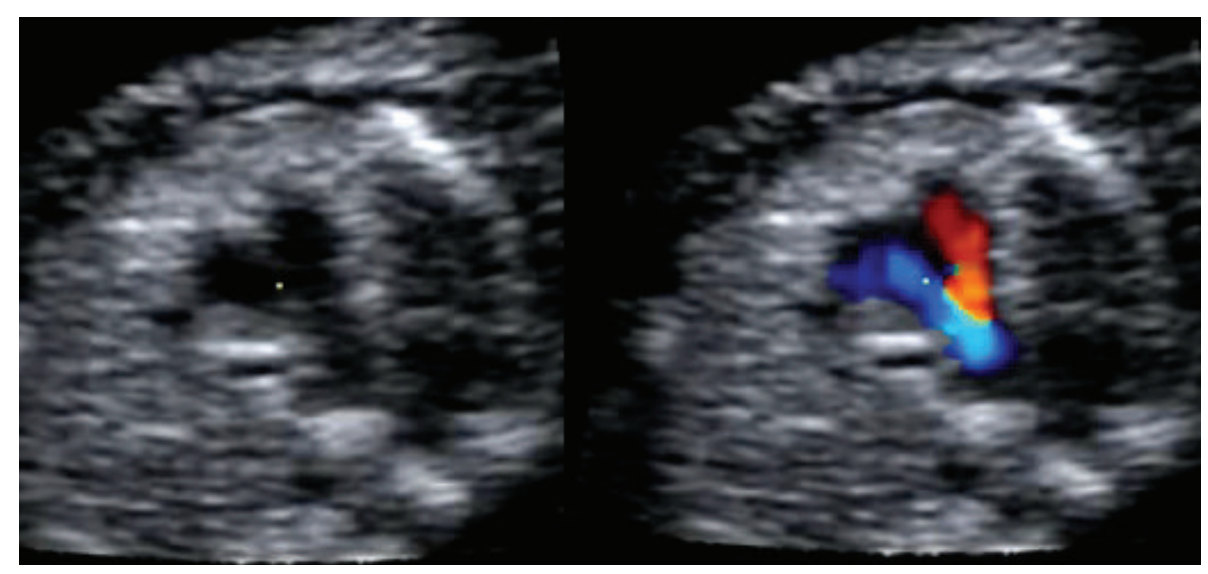

FIGURE 1: Three-vessel view illustrating retrograde blood flow in the pulmonary artery.

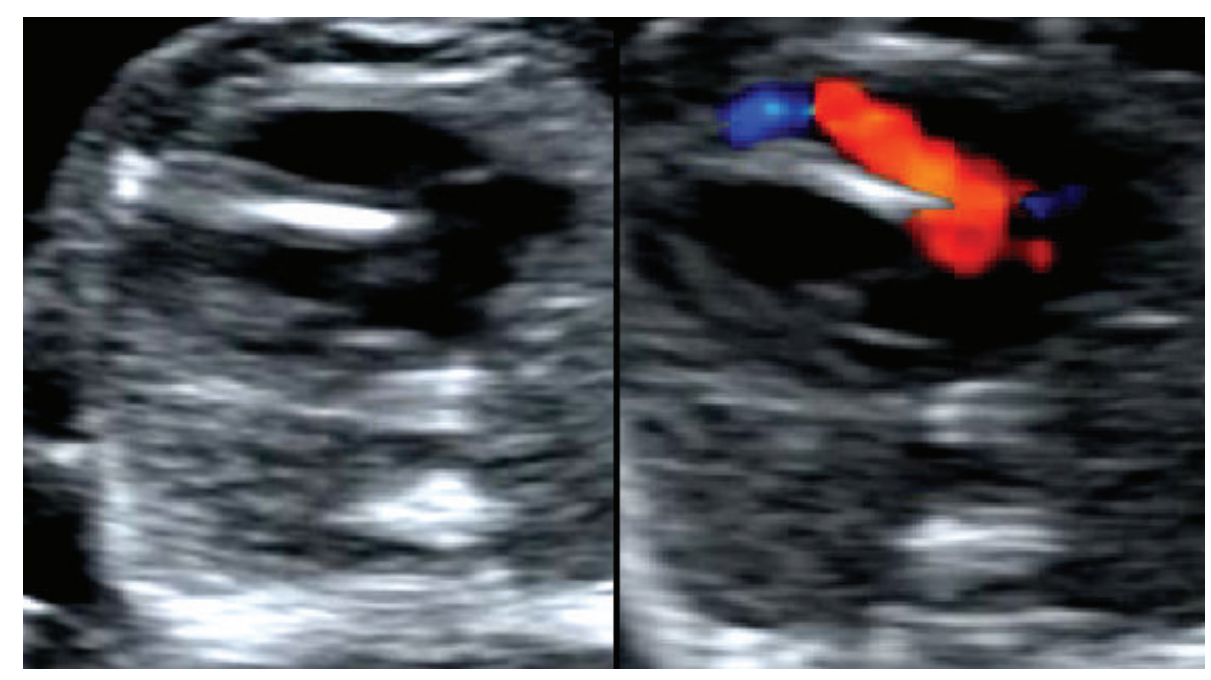

FIGURE 2: Unilateral perfusion of right ventricle in fetus with hypoplastic left heart syndrome. 


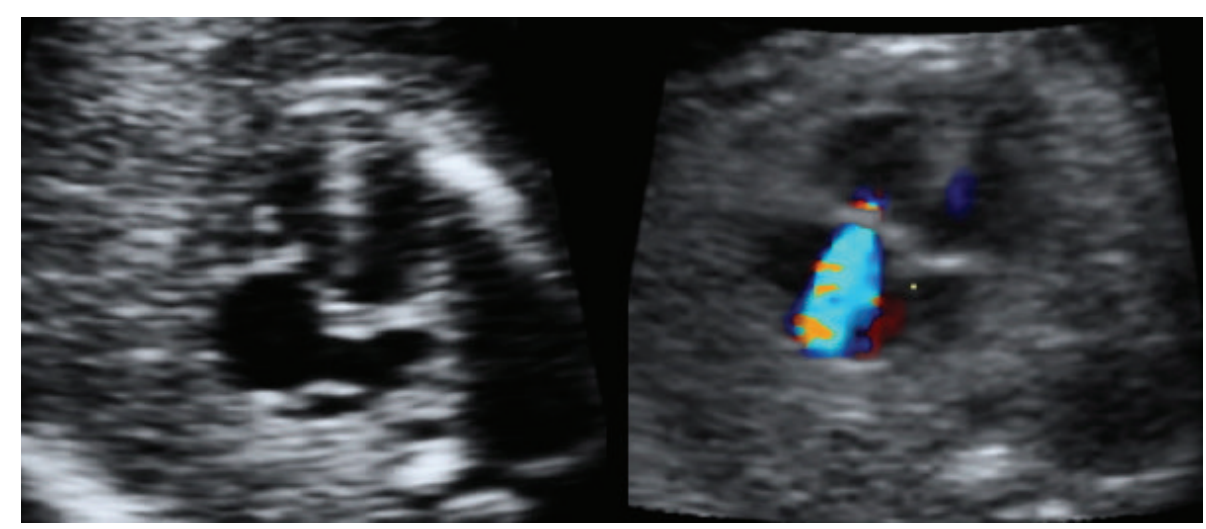

FIgURE 3: Displacement and insufficiency of the tricuspid valve (Ebstein's anomaly).

should be possible to detect prenatally. The routine second trimester scan in Norway is recommended between week 17 and 20. A detailed fetal heart scanning is easier later in the second trimester. CoA is difficult to diagnose prenatally, and malformations related to the aortic arch are the most commonly undiagnosed severe heart defects [27]. Unfortunately we missed most of aortic arch malformations in our study, and a method detecting these abnormalities is highly desirable. Small VSDs and moderate pulmonary stenosis are also commonly undiagnosed at delivery; however, these malformations are usually not life threatening shortly after birth. The high survival rate in live born children in our study may be related to high prenatal detection rate and to termination of pregnancy in fetuses with the most critical anomalies. In 10 cases the karyotype was abnormal, but there were only three cases with trisomy 21 . This last number was unexpectedly low and might be related to first trimester ultrasound examinations of high-risk women.

A possible disadvantage of using color Doppler is that all extra assessments are time consuming and routine use of color Doppler will have impact on workload in a fetal medicine unit.

We conclude that routine use of color Doppler in fetal heart scanning in a low-risk population may be helpful in the detection of major heart defects; however, still severe malformations are missed prenatally.

\section{Abbreviations}

VSD: Ventricular septal defect

ASD: Atrial septal defect

AVSD: Atrioventricular septal defect

PA: Pulmonary atresia

DA: Ductus arteriosus

TGA: Transposition of the great arteries

IAA: Interrupted aortic arch

CoA: Coarctation of the aorta

DORV: Double outlet right ventricle

HLHS: Hypoplastic left heart syndrome

HRHS: Hypoplastic right heart syndrome

TTS: Twin-twin transfusion

TOP: Termination of pregnancy
IUFD: Intrauterine fetal death

ISUOG: International Society of Ultrasound in Obstetrics and Gynecology

AIUM: American Institute of Ultrasound in Medicine.

\section{Disclosure}

No funding was received for the manuscript. The authors alone are responsible for the content and writing of the paper. The study was registered in clinical trials with identifier NCT01201486.

\section{Authors' Contribution}

T. M. Eggebø and C. Heien designed the study, C. Heien performed routine ultrasound examinations, and T. M. Eggebø performed extended ultrasound examinations when a malformation was suspected. M. Berget performed echocardiography of the children, and C. L. Ellingsen performed autopsies. All authors contributed to the writing of the manuscript.

\section{Acknowledgments}

Kari Utne, Karin Stangeland, Janne Brathetland, Sigrid Klyve, and Marit Tjessheim performed routine ultrasound examinations, Philip von Brandis performed extended ultrasound examinations, Osvald Mæle performed echocardiography in children, and Hege Ulland Dirdal performed autopsies.

\section{References}

[1] H. Dolk, M. Loane, and E. Garne, "Congenital heart defects in Europe: prevalence and perinatal mortality, 2000 to 2005," Circulation, vol. 123, no. 8, pp. 841-849, 2011.

[2] L. Allan, B. Benacerraf, J. A. Copel et al., "Isolated major congenital heart disease," Ultrasound in Obstetrics \& Gynecology, vol. 17, no. 5, pp. 370-379, 2001.

[3] M. Blyth, D. Howe, J. Gnanapragasam, and D. Wellesley, "The hidden mortality of transposition of the great arteries and survival advantage provided by prenatal diagnosis," International 
Journal of Obstetrics and Gynaecology, vol. 115, no. 9, pp. 10961100, 2008.

[4] J. A. Copel, A. S. A. Tan, and C. S. Kleinman, "Does a prenatal diagnosis of congenital heart disease alter short-term outcome?" Ultrasound in Obstetrics and Gynecology, vol. 10, no. 4, pp. 237-241, 1997.

[5] G. Sharland, "Fetal cardiac screening: why bother?" Archives of Disease in Childhood, vol. 95, no. 1, pp. F64-F68, 2010.

[6] J. S. Carvalho, E. Mavrides, E. A. Shinebourne, S. Campbell, and B. Thilaganathan, "Improving the effectiveness of routine prenatal screening for major congenital heart defects," Heart, vol. 88, no. 4, pp. 387-391, 2002.

[7] R. Chaoui, "The four-chamber view: four reasons why it seems to fail in screening for cardiac abnormalities and suggestions to improve detection rate," Ultrasound in Obstetrics and Gynecology, vol. 22, no. 1, pp. 3-10, 2003.

[8] G. Acharya, V. Sitras, J. M. Maltau et al., "Major congenital heart disease in Northern Norway: shortcomings of pre- and postnatal diagnosis," Acta Obstetricia et Gynecologica Scandinavica, vol. 83, no. 12, pp. 1124-1129, 2004.

[9] E. Tegnander, W. Williams, O. J. Johansens, H. G. K. Blaas, and S. H. Eik-Nes, "Prenatal detection of heart defects in a non-selected population of 30149 fetuses-detection rates and outcome," Ultrasound in Obstetrics and Gynecology, vol. 27, no. 3, pp. 252-265, 2006.

[10] M. Westin, S. Saltvedt, G. Bergman et al., "Routine ultrasound examination at 12 or 18 gestational weeks for prenatal detection of major congenital heart malformations? A randomised controlled trial comprising 36299 fetuses," International Journal of Obstetrics and Gynaecology, vol. 113, no. 6, pp. 675-682, 2006.

[11] A. Galindo, I. Herraiz, D. Escribano, D. Lora, J. C. Melchor, and J. De La Cruz, "Prenatal detection of congenital heart defects: a survey on clinical practice in Spain," Fetal Diagnosis and Therapy, vol. 29, no. 4, pp. 287-295, 2011.

[12] E. Tegnander and S. H. Eik-Nes, “The examiner's ultrasound experience has a significant impact on the detection rate of congenital heart defects at the second-trimester fetal examination," Ultrasound in Obstetrics and Gynecology, vol. 28, no. 1, pp. 8-14, 2006.

[13] A. McBrien, A. Sands, B. Craig, J. Dornan, and F. Casey, "Impact of a regional training program in fetal echocardiography for sonographers on the antenatal detection of major congenital heart disease," Ultrasound in Obstetrics and Gynecology, vol. 36, no. 3, pp. 279-284, 2010.

[14] C. Chew, S. Stone, S. M. Donath, and D. J. Penny, "Impact of antenatal screening on the presentation of infants with congenital heart disease to a cardiology unit," Journal of Paediatrics and Child Health, vol. 42, no. 11, pp. 704-708, 2006.

[15] L. L. Simpson, "Screening for congenital heart disease," Obstetrics and Gynecology Clinics of North America, vol. 31, no. 1, pp. 51-59, 2004.

[16] W. Lee, L. Allan, J. S. Carvalho et al., "ISUOG consensus statement: what constitutes a fetal echocardiogram?" Ultrasound in Obstetrics and Gynecology, vol. 32, no. 2, pp. 239-242, 2008.

[17] R. Chaoui and R. McEwing, "Three cross-sectional planes for fetal color Doppler echocardiography," Ultrasound in Obstetrics and Gynecology, vol. 21, no. 1, pp. 81-93, 2003.

[18] International Society of Ultrasound in Obstetrics \& Gynecology, "Cardiac screening examination of the fetus: guidelines for performing the "basic" and "extended basic" cardiac scan," Ultrasound in Obstetrics \& Gynecology, vol. 27, no. 1, pp. 107113, 2006.
[19] Fetal Echocardiography Task Force, American Institute of Ultrasound in Medicine Clinical Standards Committee, American College of Obstetricians and Gynecologists, and Society for Maternal-Fetal Medicine, "AIUM practice guideline for the performance of fetal echocardiography," Journal of Ultrasound in Medicine, vol. 30, no. 1, pp. 127-136, 2011.

[20] K. Salvesen, C. Lees, J. Abramowicz, C. Brezinka, G. Ter Haar, and K. Marsal, "ISUOG statement on the safe use of Doppler in the 11 to 13 +6-week fetal ultrasound examination," Ultrasound in Obstetrics \& Gynecology, vol. 37, no. 6, p. 628, 2011.

[21] S. Yagel, R. Arbel, E. Y. Anteby, D. Raveh, and R. Achiron, "The three vessels and trachea view (3VT) in fetal cardiac scanning," Ultrasound in Obstetrics and Gynecology, vol. 20, no. 4, pp. 340-345, 2002.

[22] E. Tegnander, S. H. Eik-Nes, and D. T. Linker, "Incorporating the four-chamber view of the fetal heart into the secondtrimester routine fetal examination," Ultrasound in Obstetrics \& Gynecology, vol. 4, no. 1, pp. 24-28, 1994.

[23] A. Del Bianco, S. Russo, N. Lacerenza et al., "Four chamber view plus three-vessel and trachea view for a complete evaluation of the fetal heart during the second trimester," Journal of Perinatal Medicine, vol. 34, no. 4, pp. 309-312, 2006.

[24] S. J. Yoo, Y. H. Lee, E. S. Kim et al., "Three-vessel view of the fetal upper mediastinum: an easy means of detecting abnormalities of the ventricular outflow tracts and great arteries during obstetric screening," Ultrasound in Obstetrics and Gynecology, vol. 9, no. 3, pp. 173-182, 1997.

[25] F. Vinals, F. Heredia, and A. Giuliano, "The role of the three vessels and trachea view (3 VT) in the diagnosis of congenital heart defects," Ultrasound in Obstetrics \& Gynecology, vol. 22, no. 4, pp. 358-367, 2003.

[26] L. Allan, "Fetal cardiac scanning today," Prenatal Diagnosis, vol. 30, no. 7, pp. 639-643, 2010.

[27] C. Wren, Z. Reinhardt, and K. Khawaja, "Twenty-year trends in diagnosis of life-threatening neonatal cardiovascular malformations," Archives of Disease in Childhood, vol. 93, no. 1, pp. F33-F35, 2008. 


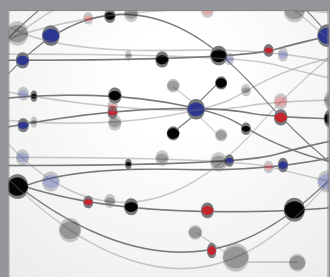

The Scientific World Journal
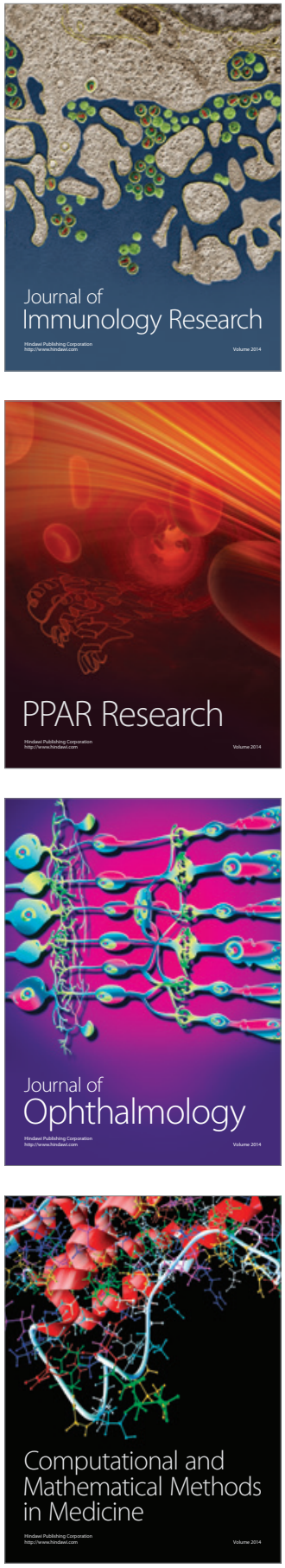

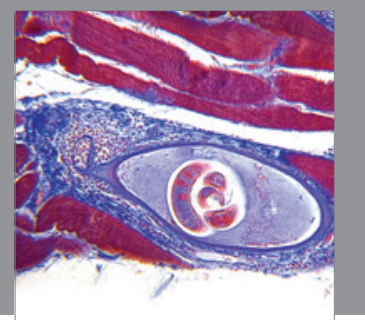

Gastroenterology

Research and Practice
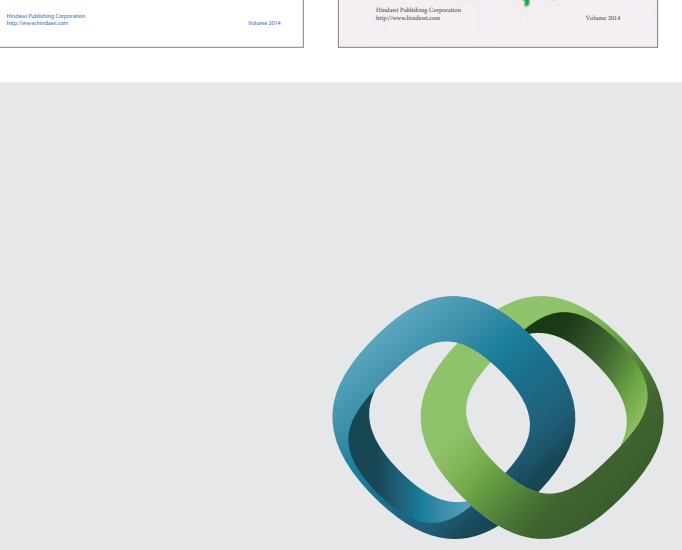

\section{Hindawi}

Submit your manuscripts at

http://www.hindawi.com
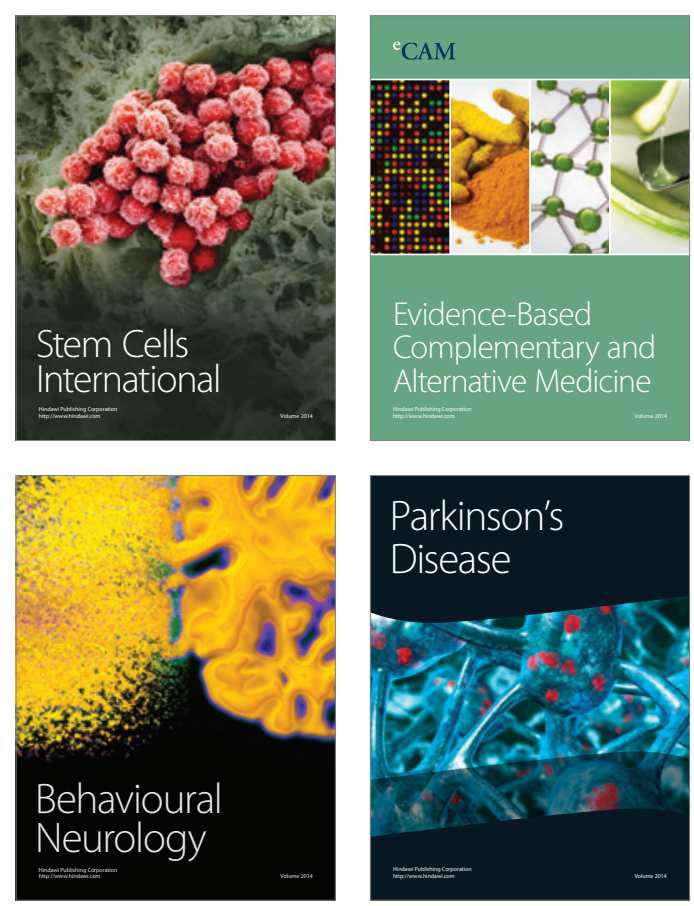

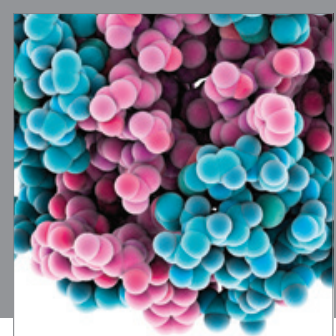

Journal of
Diabetes Research

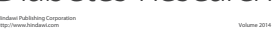

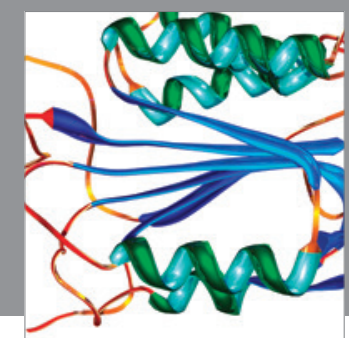

Disease Markers
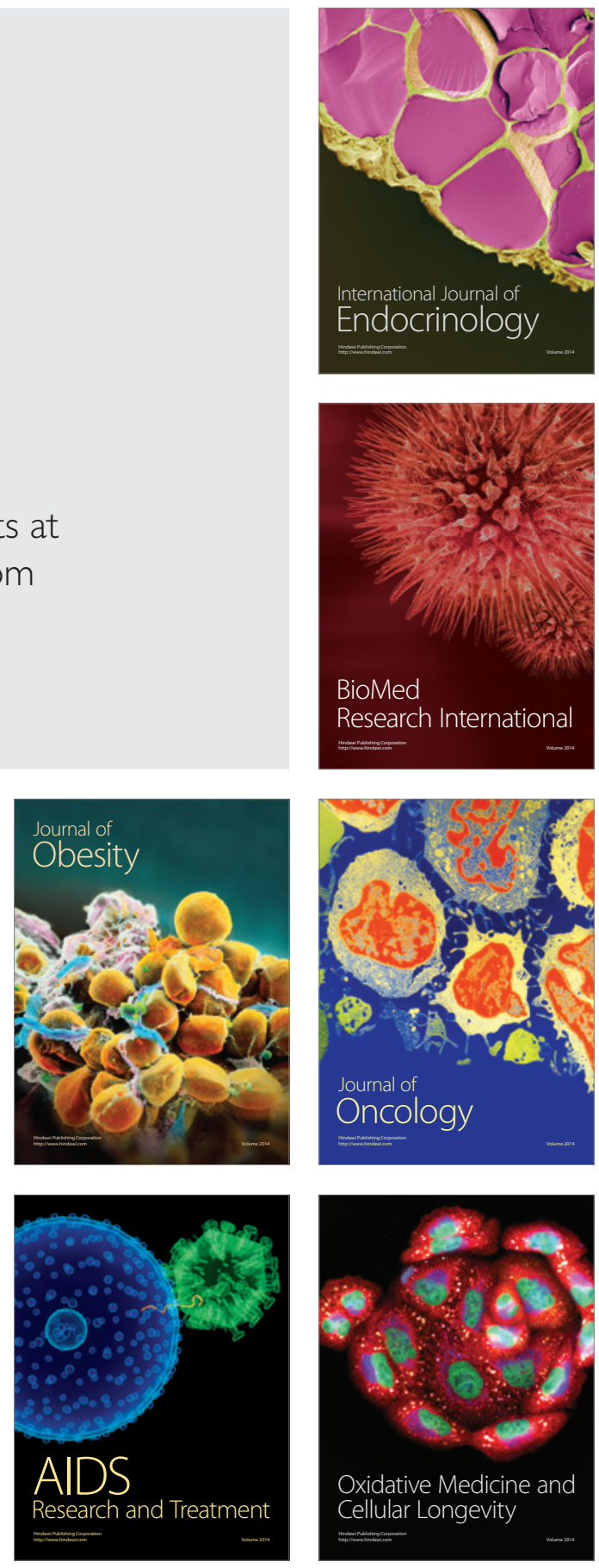